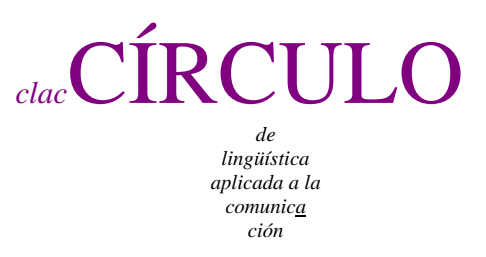

$63 / 2015$

\title{
THE INTEGRATION OF CONTACT BY IMPACT VERBS INTO THE INTRANSITIVE-MOTION CONSTRUCTION
}

\author{
Aneider Iza \\ Universidad de la Rioja \\ aneideriza at gmail com
}

\begin{abstract}
The present investigation will analyze the lexical-constructional integration of contact by impact verbs (transitive by origin) into the intransitive-motion construction. Departing from the classical works by Levin (1993), Goldberg (1995) and Faber and Mairal (1999) on contact by impact verbs, I will propose a new taxonomy that overcomes the weaknesses of previous classifications and discuss the constructional use of these verbs in real language data. Finally, I will explain the compatibility of such verbs with the intransitive-motion construction following the explanatory tools provided by the Lexical Constructional Model (Ruiz de Mendoza and Mairal, 2008a, 2008b, 2011). The main conclusions that derive from this study are that most contact-byimpact verbs are compatible with the intransitive-motion construction, this integration being possible by applying different high-level metaphors and metonymies and that all contact-by-impact verbs that are related to sound (batter, bump, crack,...) are licensed into the intransitive-motion construction thanks to the use of the high-level metonymy
\end{abstract}

Iza, Aneider. 2015.

The integration of contact by impact verbs into the intransitive-motion construction Círculo de Lingüística Aplicada a la Comunicación 63, 173-199.

http://www.ucm.es/info/circulo/no63/iza.pdf

http://revistas.ucm.es/index.php/CLAC

http://dx.doi.org/10.5209/rev_CLAC.2015.v63.50174

(C) 2015 Aneider Iza

Círculo de Lingüística Aplicada a la Comunicación (clac)

Universidad Complutense de Madrid. ISSN 1576-4737. http://www.ucm.es/info/circulo 
RESULT FOR ACTION, in which the resulting sound is taken as the action performed by the subject.

Keywords: contact by impact verbs, intransitive-motion construction, high- level metaphor, high-level metonymy

\section{Contents}

1. Introduction, 174

2. Constructions within the LCM, 176

3. Contact-by-impact verbs, 178

4. The subsumption process of contact-by-impact verbs into the intransitive-motion construction, 184

4.1. External semantic constraints, 186

4.2. Internal semantic constraints, 190

5. Conclusion, 194

References, 197

\section{Introduction}

The purpose of the present study is to analyze the lexical-constructional integration of verbs of contact-by-impact into the intransitive-motion construction (The fabric cracks and bangs in the wind; Jinny heard a car come bumping up).

Some construction types, such as the caused-motion construction, have already been analyzed in detail by construction grammarians (Goldberg 1995; Goldberg and Jackendoff 2004; Ruiz de Mendoza and Mairal 2007, 2008a) and even some articles have been published on the integration of contact-by-impact verbs into such construction (Luzondo 2007; Ruiz de Mendoza and Mairal 2008a, 2008b, 2011). On the contrary, the number of studies that deal with the intransitive-motion construction is much smaller. And, if considered in relation to verbs of contact-by-impact, previous 
publications are scarce. In her well known 1995 publication Goldberg postulates the existence of this configuration but she does not analyze it in detail; she states that the intransitive-motion configuration, which accounts for intransitive sentences expressing motion, is but a subpart of the caused-motion construction, its most distinguishing characteristic being that the external cause of the movement is not present in the production. This study attempts to show that the complexity of the intransitive-motion construction has been largely underestimated, and that the cognitive operations underlying this type of form-meaning pairing should be further explored under the light of a broader corpus of analysis.

In this scenario, the classical works by Levin (1993), Goldberg (1995) and Faber and Mairal (1999) will serve as a starting point for an exhaustive and systematic analysis of the compatibility of contact-by-impact verbs with the intransitive-motion construction. In order to pursue this goal, I will make use of the analytical tools and theoretical framework provided by the Lexical-Constructional Model (henceforth LCM; Ruiz de Mendoza and Mairal, 2008a, 2008b, 2011).

The steps of the analysis have been the following: First, I had to delimit the verbs that would be the object of this study. From the 35 contact-by-impact verbs that Faber and Mairal (1999) identified (hit, beat, strike, kick, knock, tap, crack, slap, whip, punch, hammer, smack, batter, lash, box, rap, thump, bash, crown, whack, jab, dribble, butt, swat, spank, cuff, sock, bump, club, clobber, flog, clout, cane, brain and birch (ordered by number of frequency of use according to the COCA corpus)) I eliminated crown from my study, as almost all the examples found in the corpora were related to the ceremonial placing of a crown on someone's head to invest them as a monarch or to signal the triumphant culmination of an effort or endeavor. Then, I made use of three different corpora, the British National Corpus (BNC), the Contemporary Corpus of American English (COCA) and the WebCorps to find instances of their constructional use in real language data, looking for potential constructions in which those verbs could be licensed. The results of these searches have revealed the compatibility of contact-byimpact verbs with many constructional patterns (e.g. caused-motion, intransitivemotion, resultative, and "way" construction). From these configurations, the intransitive-motion had not been considered in relation to contact-by-impact verbs in previous works. 
This study also depends mainly on the Collins Cobuild Dictionary (1987) for the definition and delimitation of the sense of the predicates included in the analysis, which revealed the most salient semantic and pragmatic properties of each of the verbs included in the initial list, noticing that they are one of the factors that license the integration of a particular verb in a given construction. On some occasions the WordReference Online Dictionary (since 1999) has been used to complement the information extracted from the Collins Cobuild Dictionary when the latter was not detailed enough.

Finally, I have tried to explain the compatibility of verbs of contact-by-impact with the intransitive-motion construction following the explanatory tools of the LCM by describing the internal and external constraints responsible for their constructional integration.

The rest of this article is organized as follows: section 2 provides an overview of the most relevant theoretical points for the development of the present study, which concern the concept of construction within the LCM, as well as some basic information on the structure of the model. Section 3 critically examines previous research on the verbs-ofcontact-by-impact and a tentative new classification of such verbs is provided, which departs in subtle but essential aspects from Levin's (1993) and Faber and Mairal's (1999) taxonomies. After these introductory sections, Section 4 starts by offering a brief description of the semantic and syntactic aspects of the intransitive-motion construction. It is then revealed which contact-by-impact verbs are compatible with the intransitivemotion configuration and such compatibility is accounted for by making use of the theoretical tools provided by the LCM (i.e. external and internal constraints), together with some proposals by Goldberg (1995) and Navarro i Ferrando (2011). The final section summarizes all the findings of the present research.

\section{Constructions within the LCM}

In Construction Grammar, Cognitive Grammar, and Cognitive Linguistics, constructions are understood as the basic units of language, a syntactic template that is paired with conventionalized semantic and pragmatic content. According to Construction Grammar in particular, a distinct construction is said to exist if one or more of its properties are not strictly predictable from knowledge of other constructions 
existing in the grammar (Goldberg 1995: 4). The LCM goes beyond Construction Grammar in that it formulates specific conditions for lexical-constructional integration to be possible. Thus, the LCM regards lexical-constructional integration as a cognitive process constrained by internal (e.g. conceptual consistency) or external principles (e.g. high-level metaphor and metonymy). In this connection, the founders of the model believe that the reason for verbs to be able to participate in different constructions lies in a correct understanding of the way internal and external constraints license lexicalconstructional subsumption, i.e. the principle-regulated fusion of a lexical template into a higher level constructional pattern.

The Lexical-Constructional Model (LCM; Ruiz de Mendoza and Mairal 2007, 2008a, 2008b, 2011; Mairal and Ruiz de Mendoza 2009; cf. Butler 2009), as a usage based, comprehensive theory of meaning construction, distinguishes four meaning construction layers for linguistic description and explanation: argument structure (level 1), pragmatic implication (level 2), illocution (level 3) and discourse, including discourse constructions and inferential activity based on high-level propositional models (level 4). Within the LCM, lexical template is a low-level semantic representation of the syntactically relevant content of a predicate, whereas a constructional template is a high-level semantic representation of syntactically relevant meaning elements abstracted away from multiple lower-level representations. A lexical template consists of a semantic module (which expresses the semantic and pragmatic parameters of predicate meaning) and a logical structure, constructed on the basis of the Aktionsart module proposed in Role and Reference Grammar (Van Valin and LaPolla 1997; Van Valin 2005). Lexical templates also contain internal variables that capture world-knowledge elements that relate to the corresponding predicate, thus indicating in what way the actor and the affected entity interrelate. The LCM uses the same metalanguage for the description of both lexical and constructional templates, thus facilitating their subsumption.

Lexical-constructional subsumption can be defined as the incorporation of lexical templates into higher-level constructional representations. In this process, constructional templates coerce lexical templates following internal and external constraints on subsumption. As noted by Ruiz de Mendoza and Mairal (2007, 2008, 2011) external constraints refer to high-level metaphoric and metonymic operation, whereas internal 
constraints deal with factors that depend on lexical class ascription, lexicalconstructional compatibility and either predicate or internal variable conditioning of external variables. Some of the most representative internal constraints include the FULL MATCHING constraint, which specifies that "there must be full identification of variables, subevents and operators between the lexical template and the constructional template” (Ruiz de Mendoza and Mairal 2008).

\section{Contact-by-impact verbs}

Contact-by-impact verbs have been studied from different perspectives over the last decades. In this section I provide a critical examination of previous research on the verbs-of-contact-by-impact departing from Levin's (1993), Goldberg's (1995), and Faber and Mairal's (1999) taxonomies in the form of lexical templates as proposed by the LCM.

Levin (1993: 150) defines contact-by-impact verbs as "verbs that describe the action of moving an entity to bring it into contact with another entity, without necessarily entailing that this contact has any effect on the second entity”. Levin (1993) distinguishes 60 verbs of contact-by-impact classified into 4 different types of verbs in consonance with their syntactic properties: Hit verbs, Swat verbs, Spank verbs, and Non-agentive verbs of contact-by-impact. This taxonomy offers in my opinion too broad assumptions regarding the occurrence of contact-by-impact verbs in the different constructions without specifying the underlying semantic and pragmatic factors that explain compatibility issues.

In addition, Levin pays no attention to the compatibility of contact-by-impact verbs with the construction that is the object of my research (i.e. the intransitive-motion construction).

In turn, Goldberg (1995: 170) following Fillmore (1970) establishes a twofold typology of hit verbs and strike verbs. For Goldberg, what distinguishes these two classes of verbs of forceful impact is whether the impacted entity is necessarily affected in a way that does not involve motion (cf. Fillmore 1970). All of the predicates included in the category of strike verbs require that the impacted entity be affected, while those in the hit group, which do allow a directional dimension to be specified, allow their direct objects to be either unaffected generally or unaffected except for the particular effect of 
motion. This classification though, does not shed light on the reasons why contact verbs are licensed or blocked in different types of constructions and has been proved largely inconsistent by Luzondo’s (2007) corpus-based study on the subsumption of contact-byimpact verbs into the caused-motion construction (E.g. They yanked it out and socked him into the hospital; Sharon slapped them out of the government; A worry smacked me out of bed around, etc.). Luzondo (2007: 173) on the basis of corpus data, has proved that the second argument (him, them, me...) is indeed affected by the particular effect produced by the predicate when subsumed into the caused-motion construction. In this manner we may understand the direct object to receive the impact denoted by the verbal predicate, and by being unable to absorb the impact, to be forced to move along a designated path.

Finally, for my research, I've made use of Faber and Mairal's (1999) classification. Unlike Levin's and Goldberg's proposals, Faber and Mairal's typology is based on the semantic properties of the verbs. For Faber and Mairal (1999), the notion of contact is defined as "to touch somebody/something quickly, using a lot of force" and each contact-by-impact verb contains both notions of motion and contact. These verbs, Mairal (2002) explains, belong to the general semantic domain of action verbs, being hit the generic term that defines the syntactic and semantic universe of discourse of contact-by-impact verbs. In this line, Faber and Mairal (1999), in their classification of contact-by-impact verbs, put forward some parameters for their classification. These semantic parameters allow a rich set of semantic distinctions, which provide a sound starting point for my study on the compatibility of contact-by-impact verbs with the intransitive-motion construction. The full classification can be found below:

1) Type of Blow

a. Intensity

i. Lightly: tap, cuff

ii. Hard: strike, punch, thump, beat, knock, clobber, clout, batter, cane, whip, lash, birch

iii. Very hard: sock, knock, clobber, bash, kick, flog, crown, brain

b. Sound

i. Sharp, punctual, loud: crack, whack, knock, smack, jab

ii. Dull, punctual: thump, bump 
c. Movement

i. Quick: tap, rap, swat, jab

ii. Swinging: swat

iii. Iterative: rap, jab, beat, batter, clobber, cane, whip, lash, flog, birch, hammer.

2) Instrument

d. Hand: hit, cuff, strike, swat

e. Fist: punch, box, sock, thump, jab, batter, clout

f. Palm: slap, spank, box, smack

g. Head: butt

h. Foot: kick, dribble

i. Object

i. Club: $c l u b$

ii. Hammer: hammer

iii. Cane: cane

iv. Whip: whip, lash

v. Newspaper/fly swatter: swat

vi. Birch stick: birch

vii. Unspecified object: batter, clout

2) Entity affected

a. Head: crown, brain

b. Buttocks: spank

c. Ear: box

d. Ball: dribble

3) Reason
a. Anger: strike
b. Desire to hurt: spank, cane, whip, lash, flog, birch.
c. Desire to move something: hit, strike.

Once having said that, another important characteristic of contact-by-impact verbs is that there is a direct correlation between the notions of impact and sound. Our world knowledge tells us that when an object enters into contact with another usually there is a sound that emanates from the collision as a result of the impact. Faber and Mairal 
(1999), being aware of this, integrated in their classification of the contact-by-impact verbs a sound parameter for the verbs bump, crack, jab, knock, smack, thump and whack. In some usages of these verbs, it is the use of a high-level metaphor or metonymy (external constraints, as proposed by the LCM) that licenses the integration of such verbs into different constructions, such as the caused-motion construction. Consider the following examples:

(1) He slaps the glass down on the table (HGU 3144 BNC)

(2) She began cracking eggs into a bowl (CK0 1994 BNC)

(3) He turned away with a groan and thumped the mantle of the fireplace with his hand (G1S 366 BNC)

In these examples the contact-by-impact verbs merge the action performed by the subject with the sound produced by that action. By way of illustration, the verb crack in example (7) expresses a sound that is produced at the impact of the eggs to be broken. These sentences are therefore licensed thanks to the use of the high-level metonymy ACTION FOR RESULT, in which the resulting sound is taken as the action performed by the subject. Therefore, these verbs are inevitably linked to the final part of the event. One of the parameters of Faber and Mairal's classification (i.e. instrument parameter), however, deserves some discussion. These authors listed the predicates sock and batter within the group of verbs which describe an action performed with the "fist" as an instrument. Closer consideration of the meaning of these verbs in the Collins Cobuild, WordReference, and Oxford dictionaries reveals, however, that they are not necessarily performed with this part of the body.

Faber and Mairal's classification also shows a certain degree of inconsistent overlapping as when the same verb is included in two different instrument categories such as "unspecified object" and "fist" (e.g. clout), or “fist” and "palm” (e.g. box). My analysis has thus shown the need for a new taxonomy of contact-by-impact verbs which makes use of more specific classification criteria such as punishment for the reason of the blow and which avoids the repetition of the predicates in different categories. In an attempt to solve these weaknesses and to provide a more fine-grained semantic characterization of contact-by-impact verbs, I propose the following taxonomy: 
Table 1.Taxonomy proposal for contact-by-impact verbs

\begin{tabular}{|c|c|c|c|}
\hline \multicolumn{4}{|c|}{ Taxonomy proposal for contact-by-impact verbs } \\
\hline \multirow{3}{*}{$\begin{array}{c}\text { SYNTACTIC } \\
\text { PARAMETERS: TYPE OF } \\
\text { VERB }\end{array}$} & \multicolumn{2}{|l|}{ HIT VERBS } & $\begin{array}{l}\text { Bash, Batter, Beat, Bump, Butt, } \\
\text { Clout, Crack, Hammer, Hit, Kick, } \\
\text { Knock, Lash, Rap, Slap, Smack, } \\
\text { Strike, Tap, Thump, Whack }\end{array}$ \\
\hline & \multicolumn{2}{|l|}{ SPANK VERBS } & $\begin{array}{l}\text { Birch, Brain, Cane, Clobber, Club, } \\
\text { Cuff, Flog, Sock, Spank, Whip }\end{array}$ \\
\hline & \multicolumn{2}{|l|}{ SWAT VERBS } & Box, Dribble, Jab, Punch, Swat \\
\hline \multirow{16}{*}{$\begin{array}{c}\text { SEMANTIC } \\
\text { PARAMETERS }\end{array}$} & \multirow{5}{*}{ 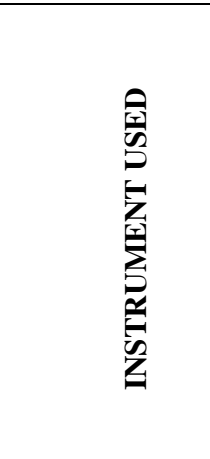 } & \multirow{3}{*}{$\begin{array}{l}\text { A part of the } \\
\text { human body }\end{array}$} & $\begin{array}{l}\text { Hand/fist: Batter, Box, Cuff, } \\
\text { Hammer, Knock, Punch, Slap, } \\
\text { Smack, Sock, Thump }\end{array}$ \\
\hline & & & Foot/Leg: Kick, Dribble \\
\hline & & & Head: Butt \\
\hline & & \multirow{2}{*}{$\begin{array}{l}\text { An external } \\
\text { instrument }\end{array}$} & $\begin{array}{l}\text { Stick-like: Beat, Birch, Cane, Club, } \\
\text { Flog, Lash, Whip }\end{array}$ \\
\hline & & & Other: Hammer (Hammer), etc. \\
\hline & \multirow{3}{*}{ 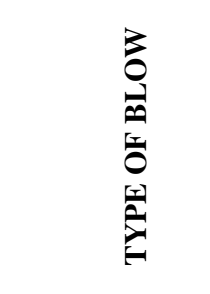 } & Sharp, Punctual & Brain \\
\hline & & Quick, Swinging & Rap, Swat \\
\hline & & Iterative & $\begin{array}{l}\text { Batter, Beat, Dribble, Hammer, } \\
\text { Rap, Spank, Tamp, Tap }\end{array}$ \\
\hline & \multirow{3}{*}{ 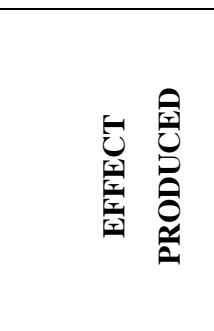 } & \multicolumn{2}{|c|}{$\begin{array}{l}\text { Sound: Batter, Bump, Crack, Hammer, Knock, Slap, } \\
\text { Smack, Tap, Thump }\end{array}$} \\
\hline & & \multicolumn{2}{|c|}{$\begin{array}{l}\text { Movement: Butt, Dribble, Hit, Bump, Jab, Knock, } \\
\text { Strike }\end{array}$} \\
\hline & & \multicolumn{2}{|c|}{$\begin{array}{l}\text { Change of state (broken, damaged, etc.): Crack, Crash, } \\
\text { Hit }\end{array}$} \\
\hline & \multirow{2}{*}{ 空 } & \multicolumn{2}{|c|}{ Human body: Brain, Spank, Box } \\
\hline & & \multicolumn{2}{|c|}{ Other: Dribble (ball) } \\
\hline & \multirow{3}{*}{ 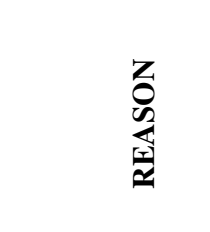 } & \multicolumn{2}{|l|}{ Anger: Hammer } \\
\hline & & \multicolumn{2}{|c|}{$\begin{array}{l}\text { Punishment: Batter, Box, Beat, Cane, Flog, Lash, Spank, } \\
\text { Whip }\end{array}$} \\
\hline & & \multicolumn{2}{|l|}{ Other reasons } \\
\hline
\end{tabular}


In addition to overcoming those weaknesses of Faber and Mairal's (1999) taxonomy mentioned above, this classification also takes advantage of Levin's (1993) insights into the syntactic properties of the corresponding predicates. Thus, this taxonomy has two distinctive parts; the first part classifies contact-by-impact verbs according to their syntactic properties, whereas in the second part these same verbs are classified according to their most salient semantic features. In this manner, taking Faber and Mairal's (1999) lexematic classification of contact-by-impact verbs as a basis, I have applied Levin's (1993) taxonomy and classified the contact-by-impact verbs listed in Faber and Mairal's (1999) classification into spank, swat and hit verbs for a richer taxonomy to include syntactic as well as semantic aspects of the verbs under study. For the choice of the semantic parameters that define the contact-by-impact verbs, I have followed Faber and Mairal’s (1999) parameter proposal with some variation:

(a) Some predicates by definition allow to be classified in more than one subcategory (e.g. the predicate hit can affect a human part or an external object). In these cases I have opted to omit the predicates in question to facilitate the classification and only write the most salient predicates for each subcategory.

(b) I have omitted the parameter of intensity in Faber and Mairal's (1999) classification as corpus data has shown that the intensity of the blow depends more on the context than on the predicate itself (e.g. He knocked quietly in order to be heard only by her vs. They knock everybody out the way).

(c) I have divided the parameters instrument and entity affected in Faber and Mairal's (1999) classification into "a part of the human body" and "an external object” instead of having a numerous list of subcategories (fist, palm head, foot, palm, birch stick, unspecified object...) as this simplifies the taxonomy and helps explaining the subsumption of some predicates into different constructions (see sections 4 and 5 ).

(d) Finally, I have added the subcategory "punishment” for the reason parameter as it has proved crucial for the subsumption of the contact-by-impact verbs into the intransitive-motion configuration (see section 4).

After the elaboration of this taxonomy, my data further shows that hit verbs (bash, batter, beat, bump, butt, clout, crack, hammer, hit, kick, knock, lash, rap....) are by far more frequent than spank verbs (birch, brain, cane, clobber, club, cuff, flog, ...) or swat 
verbs (box, dribble, jab, punch, and swat) by comparing the number of entries that the COCA corpus listed.

4. The subsumption process of contact-by-impact verbs into the intransitive-motion construction

This section describes the semantic and syntactic aspects of the intransitive-motion construction and studies the compatibility of contact-by-impact verbs (transitive by definition) with the intransitive-motion construction. Such compatibility or the lack of it is accounted for my means of the theoretical tools provided within the LCM (i.e. the external and internal constraints). The analysis is further enriched with ideas put forward by Goldberg (1995) and Navarro i Ferrando (2011).

To account for intransitive sentences expressing motion, Goldberg (1995: 70, 160) briefly deals with the intransitive-motion construction. This construction, just like the caused-motion construction, can add a motion interpretation to verbs that do not lexically code it (e.g. she bumped into something cold), where no external cause for the movement is presented. It is therefore implied that this construction is a subpart of the caused-motion construction whose semantic structure is X MOVES Y, where Y denotes the path of motion followed by X. Unfortunately Goldberg does not go any further into the semantics of this construction, which our data prove essential in relation to its integration with contact-by-impact verbs.

The intransitive-motion configuration, as its name indicates, is characterized by a change of location or a movement of the subject as denoted by the verb. Taken the above definition of this construction into account, the LCM proposes the following constructional template for the intransitive-motion configuration:

[do’ (x) [BECOME be-LOC’ $(\mathrm{x}, \mathrm{z})]$

In this logical structure, the following elements can be identified:

1. An entity (x) does an action (do).

2. That entity (x) ends at location (z) by the effect of the action (do).

3. The expression BECOME be-LOC'encodes the meaning 'change of location'. Therefore, the intransitive-motion construction has two arguments: a mover (x) and a path encoded by a locative phrase, being $\mathrm{z}$ the end point of the path accomplished by (x). 
Table 2. Compatibility of the contact-by-impact verbs and the intransitive-motion construction.

\begin{tabular}{|c|c|}
\hline $\begin{array}{l}\text { Contact-by-impact verb that are } \\
\text { compatible with the intransitive-motion } \\
\text { construction }\end{array}$ & $\begin{array}{l}\text { Contact-by-impact verbs that are } \\
\text { incompatible with the intransitive-motion } \\
\text { construction }\end{array}$ \\
\hline Bash & Birch \\
\hline Batter & Box \\
\hline Beat & Brain \\
\hline Bump & Cane \\
\hline Butt & Clobber \\
\hline Clout & Club \\
\hline Crack & Cuff \\
\hline Dribble & Flog \\
\hline Hammer & Spank \\
\hline Hit & \\
\hline$J a b$ & \\
\hline Kick & \\
\hline Knock & \\
\hline Lash & \\
\hline Punch & \\
\hline Rap & \\
\hline Slap & \\
\hline Smack & \\
\hline Sock & \\
\hline Strike & \\
\hline Swat & \\
\hline Tap & \\
\hline Thump & \\
\hline Whack & \\
\hline Whip & \\
\hline
\end{tabular}


Neither Levin (1993) nor Goldberg (1995) discussed the possibility of introducing contact-by-impact verbs into intransitive constructions such as the intransitive-motion configuration. In fact, in Levin's (1993: 148-156) taxonomy of contact-by-impact verbs we find that all class members are agentive verbs that require at least two arguments for the sentence construction, being the agent of the action mostly an animate entity. Gao and Cheng (2003: 487) also misanalyse these verbs, as for these authors, "the compulsory agentive animate subject [of contact-by-impact verbs] frames the syntactic structure as transitive verbs taking at least two arguments expressed as subject and object."

Contrasting the assumptions of Levin (1993), Gao and Cheng (2003), and Goldberg (2006) above, and after a close examination of the 34 contact-by-impact verbs selected for this study (see Table 2), the following verbs have been found to participate in the intransitive-motion configuration: bash, batter, beat, bump, butt, clout, crack, dribble, hammer, hit, jab, kick, knock, lash, punch, rap, slap, smack, sock, strike, swat, tap, thump, whack, and whip. From these, all the verbs listed under the category hit verbs in my taxonomy of contact-by-impact verbs (see Table 2) can be subsumed into the intransitive-motion construction when high-level metaphors and metonymies are applied in the interpretation of the sentences.

Sections 4.1 and 4.2 offer an explanation of the compatibility issues of the intransitivemotion construction with verbs of contact-by-impact in terms of the external and internal constraints at work in their subsumption.

\subsection{External semantic constraints}

As could be seen in Table 2 above, most contact-by-impact verbs can be found to work in the intransitive-motion construction. Making use of the theoretical and explanatory tools provided by the LCM, I would like to deal now with some of the external constraints (high-level metaphors and metonymies) that allow the lexical-constructional subsumption of contact-by-impact verbs into the intransitive-motion configuration. Consider the following sentence:

(4) We must hit back with the truth (HPC 366 BNC)

This sentence is possible by applying the high level metaphor A COMMUNICATIVE ACTION IS AN EFFECTUAL ACTION. This metaphor licenses a subcategorial 
conversion process whereby the receivers of the message (the people that will hear the truth) are seen as if directly affected by the action of the speakers turning back to hit the listeners with the truth. The truth, when heard, is supposed to be so hard to assume that it will have an impact on the hearers, as if the speakers would physically act upon them. A semantically similar predicate to hit is strike, which allows for examples like the following:

(5) The next day Signor Merli came to the bank, ostensibly on business, and whispered to me that some of the prisoners had decided to leave their hiding places and strike out across the Via Emilia towards the high Apennines (G3B 1032 BNC)

In this case, the high-level metaphor AN ACTIVITY IS AN (EFFECTUAL) ACCOMPLISHMENT allows us to interpret the originally transitive predicate strike in terms of an intransitive structure of the intransitive-motion kind. In example (10) above, the prisoners are understood to hit an imaginary barrier between their hiding places and the Via Emilia allowing their movement across it. Consider the following example:

(6) Bob expertly trotted his mount into position, gave me a raised-eye query about readiness and kicked forward into an accelerating gallop (BNC, ADY 1447)

In example (11) the entity that receives the impact (the horse) is omitted. Instead, Bob on his horse is understood to move along a designated path by the action of kicking. This is a case of a metonymic shift from elided Bob to Bob's horse (CONTROLLER FOR CONTROLLED). Kick expresses the manner of instigating an activity (motion forward). The use of a manner verb in a motion configuration is typical of what Talmy (2000) has called satellite-framed languages like English, which, unlike verb-framed languages like Spanish, expresses path of motion through a satellite rather than through the verb (cf. He staggered into the room/Entró en la habitación tambaleándose). So, kick belongs naturally in a verb slot within a motion construction. What is less trivial is the fact that the sentence under analysis makes figurative use of the satellite part of the intransitive-motion construction to express a gradual change of state rather than the path of motion: into an accelerating gallop does not code path of motion but the way in which motion takes place as a result of Bob's instigation through kicking. This is possible through the licensing activity of the metaphor CHANGES OF STATE ARE 
CHANGES OF LOCATION (Lakoff, 1993; Lakoff and Johnson, 1999). In turn, path of motion is expressed by the adverb forward in a generic way (it could have been further specified, for example, by saying kicked forward across the grass/into the horse stall, etc.).

Example (12) bellow, extracted from the COCA corpus, shows the application of the high-level metaphor AN ACTIVITY IS AN (EFFECTUAL) ACCOMPLISHMENT, which allows us to interpret the originally transitive predicate hammer in terms of an intransitive structure where the action performed by the woodpecker results in the alteration of the tree's structure:

(7) Woodpeckers hammer into the soft, woody pulp of the saguaro, providing cavities that are home...(COCA, 1990)

Fig.1. AN ACTIVY IS AN (EFFECTUAL) ACCOMPLISMENT metaphor.

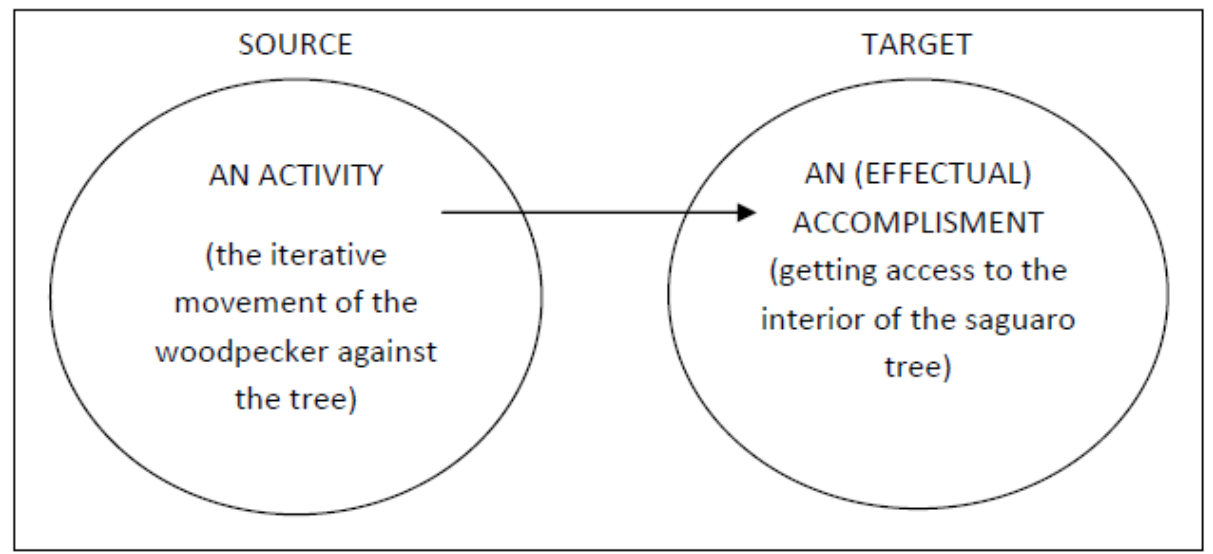

Similar mappings have been found at work in other hit verbs in my taxonomy (e.g. The waves beat into the ship, so that it was now full; the hospital was moving away from him like a phantom ship, butting through the September mists; Sharp gusts of knife-like wind clouted into the stout trees, sending them trembling...) thus licensing their subsumption with the corresponding predicates.

In other hit verbs in my taxonomy (e.g. knock, slap, lash, bash) the high-level metaphor AN EFFECTUAL ACTION IS CAUSED MOTION is the responsible for the subsumption process, as in the following examples:

(a) My knee accidentally knocked against the table (WebCorps, 2010)

(b) He was slapping about with a dustpan and brush, getting up the worst of the spilled coffee and other foods (BNC, GV2 1765) 
(c)...so she keeps her wings close to her sides as far as she can and lashes out with her feet (BNC, F9F 523)

(d) One of the two cars got a puncture and the other vehicle bashed into the back of them (BNC, CAD 3474)

(e) The driver watched in astonishment as the car whacked into the side of his vehicle (BNC, CBF 13172)

The last high-level metaphor found at work in the subsumption of hit verbs into the intransitive motion construction is AN EXPERIENTIAL ACTION IS AN EFFECTUAL ACTION, as in Someone rapped against the window or The Land Rover bumped along the track.

Another interesting finding is that all contact-by-impact verbs that are related to sound in my taxonomy (see Table 1) are licensed into the intransitive-motion construction. This is the case for instance, with verbs such as batter, bump, crack, hammer, knock, slap, smack, tap and thump.

(9) Her head went down sharply, cracking against the top of the wall, stunning her (BNC, FRF 3991)

In this example the verb crack merges the action performed by the subject (the head going down to hit the wall) with the sound produced by that action (crack). This sentence is licensed thanks to the use of the high-level source-in-target metonymy RESULT FOR ACTION, in which the resulting sound (i.e. crack) stands for the action which originates it.

Fig.2. RESULT FOR ACTION metonymy.

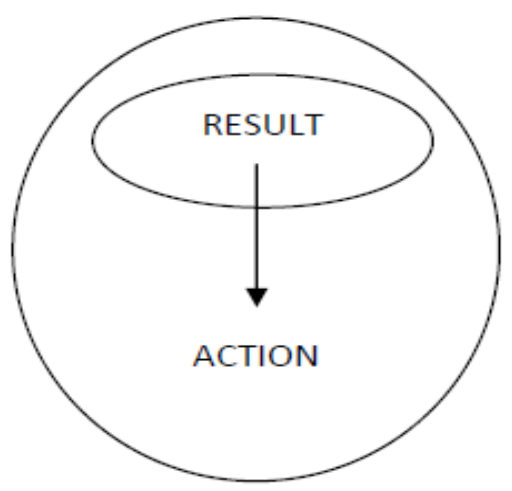

The same explanation accounts for the following examples in which the verb of contactby-impact expresses a sound: 
(10) Then it knocked against the inn door and we did not breathe (BNC, FSJ 194)

(11) A large hand smacked into his mouth and although he bit at it the thumb was forced like a gag between his teeth (BNC, ADA 1257)

(12) The train kept hammering toward the station (COCA, 2004)

(13) His heavy footsteps were thumping nearer and nearer when the root of a tree sent him sprawling. (BNC, B0B 474)

\subsection{Internal semantic constraints}

Let us now explore which internal constraints play a role in the subsumption of contactby-impact verbs with the intransitive-motion construction. As mentioned in section 3, the effect of motion constraint proposed by Goldberg for contact-by-impact verbs, which allows her to distinguish between strike verbs and hit verbs, states that "if the action denoted by the verb implies an effect other than motion, then a path of motion cannot be specified” (Goldberg 1995: 170).

This statement that Goldberg (1995) put forward in relation to the caused-motion construction is also applicable to the intransitive-motion construction. As explained above, the intransitive-motion construction requires a change of location or direction of motion to be specified, and if the action denoted by the verb implies an effect other than motion, then a path of motion cannot be specified making impossible the realization of the intransitive-motion configuration (e.g. He socked through the makeshift windowpane vs. He socked the makeshift windowpane, where there is no motion encoded from the part of the subject). This constraint also explains that when a path argument is present, the direct object of a transitive verb can only be interpreted as trajectory, it cannot be viewed simultaneously as trajectory and impacted entity, and this is precisely what licenses the intransitive-motion construction.

As seen in the example above (e.g. He socked through the makeshift windowpane vs. He socked the makeshift windowpane), in many cases the motion expressed by the intransitive-motion configuration of verbs of contact-by-impact is introduced through the use of a prepositional phrase (henceforth, PP).

As Navarro i Ferrando (2011) noted, the spatial particles of these PPs condition the use of predicates of change of placement in utterances denoting changes of relation and 
placement. By way of illustration, consider the spatial particles into, over and onto, which contribute the semantic prime MOVE or [BECOME be-LOC (x)], that is, they express a trajector's change of location. For this author, the construction alone cannot coerce a lexical item into subsumption. Conversely, it is the spatial particle (into, onto, over) or the lexical verb (hit, beat, strike, etc.) that contributes the 'change of location' sense. This is why Navarro y Ferrando believes that spatial particles contribute some semantic content to the constructions they occur in, rather than being just mere formal devices marking a locative argument.

By way of illustration, consider the different semantic content conveyed by the preposition into in the same contact-by-impact verbs in the following examples from my corpus:

(14) The motorbike bashed into it and when he bashed into him he crashed (BNC, KCA 2341)

(15) He saw Gazzer's fingers jab ferociously into Simon's face; Simon slacken his grip and Gazzer twist away, grab hold of a girder with both his hands, and haul himself up it (BNC, ACB 1929)

(16) I punched into him, pulling a strangled cry from his lips (WebCorps, 2011)

(17) My body rapped into his (WebCorps, 2012)

(18) This finger slaps into that one as wrist gets sloppy (BNC, ARP 805)

(19) When her red boots stepped on to the pavement the shock which smacked into her was conveniently attributed to the cold (BNC, ADA 1307)

In other cases, the existence of a PP in the construction can be a blocking factor for the elaboration of an intransitive-motion construction.

Corpus evidence reveals that spank verbs (see Table 2) with instrument can only be used in the with alternation if the instrument is further specified, except for spank, which is used as a generic verb of punishing by hitting. The particularity of spank can be accounted for by means of the high-level metonymy SPECIFIC FOR GENERIC, in which a domain expansion allows one type of punishing by hitting (spank-originally with the hand) to stand for any type of punishing by hitting. Compare the following examples:

- spanked me with her left hand

- spank me with her hand 
- *caned me with his cane

- caned me with his brand new cane

- *whipped me with his whip

- whipped me with a rough long whip

- clubbed me with a massive fuller club

- *clubbed me with a club

Fig.3. SPECIFIC FOR GENERIC metonymy

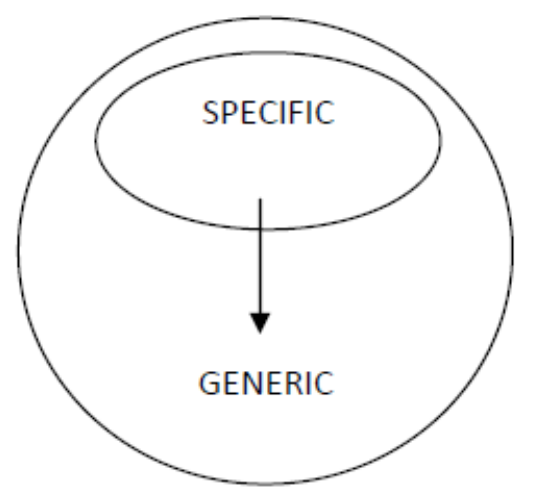

A more detailed analysis of the corpus data reveals that there are further semantic constraints operating on the subsumption of contact-by-impact verbs into the intransitivemotion construction. It has thus been noticed that the predicates that are related to the human body listed under the entity affected parameter in my classification (i.e. brain, spank, and box) (see Table 1) never take part in the intransitive-motion configuration. This can be explained by our world knowledge, which tells us that it is impossible to separate a part of our body from the rest to make it move by itself as a result of the action denoted by the verb. This is the case with predicates such as brain and box, in which the entities affected are the head and the ears respectively (e.g. *He boxed towards me; *He brained against her). The verb dribble on the contrary, which is defined as "kicking or tapping a ball quickly in order to keep it moving” (Collins Cobuild Dictionary) allows its subsumption into the intransitive-motion configuration, because the entity affected (the ball) is not a part of the human body, as can be seen in He dribbled out of the penalty area or The ball shot dribbles about the length of the average back garden.

As pointed out in previous sections, all hit verbs are compatible with the intransitivemotion construction. In section 4.1 I have presented some external constraints licensing such compatibility. In addition, it should be taken into account that because the INTERNAL VARIABLE CONDITIONING internal constraint is operating over hit verbs, movement is intrinsic to the definition of such group of verbs (according to the 
definition of hit in the Collins Cobuild Dictionary), whereas spank verbs do not necessarily entail motion, being closer to the notion of punishment and repetition. The LCM attributes this fact to the INTERNAL VARIABLE CONDITION internal constraint being at work in the subsumption of these predicates.

The few contact-by-impact verbs that do not allow their subsumption into the intransitivemotion configuration are birch, box, brain, cuff, cane, clobber, club, flog, and spank, which except for box (a swat verb) happened to be all listed under the category of spank verbs in my taxonomy (see Table 1). In the spank group, only the predicates whip and sock are licensed into the intransitive-motion construction.

A plausible explanation for this asymmetry may be found in the semantics of the verbs. As pointed by Mairal and Ruiz de Mendoza (2009: 188), some cases of subsumption may require further constraining principles. As a matter of fact, the predicates birch, cane, cuff, and whip, although very similar semantically, differ as to whether the notion of punishment is part of their meaning. According to the Wordreference Dictionary Online this is the case with birch, cane and cuff. In the case of the predicate whip, the aim of the corresponding action does not necessarily entail punishment by definition; we can whip someone to punish him, but also to make him move or for many additional reasons. In this connection, it should further be noticed that an utterance like I whipped my whip in the air is correct, meaning that the subject is hitting the air without having a specific entity in mind to which the impact is directed. On the contrary, it is not possible to say *I caned my cane in the air, nor * I birched my birch in the air.

In contrast with the first example where the impact is not addressed to anybody in particular, the last two examples need a victim, a person that will receive the punishment. This is why whip can be used in the intransitive-motion configuration unlike cane or birch which always need a patient (a direct object) that will receive the punishment.

A parallel explanation applies to the predicates box and flog which Levin (1993) did not include in her taxonomy but which are present in Faber and Mairal's (1999) classification. These predicates also entail a sort of punishment, not allowing the intransitive-motion construction due to the need of a patient by definition. Thus, as Pérez-Hernández and Peña (2009: 70) stated in relation to speech act predicates, some examples show that the external constraints that regulate the processes of constructional subsumption are not only cognitive in nature (i.e. high-level metaphors and metonymies) as proposed by Ruiz de Mendoza and Mairal (2006, 2007), but may be due to pragmatic aspects of what constitutes human behavior (see also Pérez-Hernández (1996, 2009, 2012, 2013) and Pérez-Hernández and Ruiz de Mendoza (2011) on this issue). Such pragmatic information 
is part of the semantics of the corresponding predicates and should be included in their lexical templates, so that this information can, at a later stage, be considered when looking into the internal constraints operating in their subsumption into different construction. In the case of the predicates under consideration, the internal constraint at work is that of LEXICAL BLOCKING (Mairal and Ruiz de Mendoza 2009: 188) where one of the components of the lexical template (i.e. the punishment notion) can block the fusion with a certain construction (in this case, the intransitive-motion).

As far as the predicate club is concerned, the impossibility for its integration into the intransitive-motion might originate in the type of instrument used for the performance of the action. The predicate club arises from a metonymy of the OBJECT FOR ACTION type. A club is a heavy stick with a thick end. Being this object so heavy it makes it hard for the user of the object (the performer of the action) to move to a different location while using it. The specification of this type of word knowledge in its lexical templates paves the way for the LEXICAL BLOCKING internal constraint to disallow its subsumption with the intransitive-motion configuration.

In this section it has been pointed out, on the basis of corpus data, that most contact-byimpact verbs can also merge with the intransitive-motion construction, something that previous authors such as Levin (1993) or Goldberg (1995) left unnoticed. In addition, I have offered explanations for those cases in which this subsumption is not possible in terms of the internal and external constraints proposed by the LCM.

\section{Conclusion}

The present research has tried to offer an inventory of pragmatic and cognitive constraints that are at work in the licensing of contact-by-impact verbs in their subsumption with the intransitive-motion construction.

For this purpose I have made use of the theoretical tools provided by the LCM. The lexical template for contact-by-impact verbs proposed by Mairal (2002) serves as the starting point to the subsumption of contact-by-impact verbs with the constructional templates of the construction in question, in which I have found these verbs are compatible. This combination of lexical and constructional information explains the subcategorial conversion undergone by some of the contact-by-impact verbs. Moreover, I have also shown how the constructional subsumption itself is granted by a number of external constraints of a cognitive and pragmatic nature as proposed by the LCM (high- 
level metaphors and metonymies) and when this subsumption is not possible, reasons for this incompatibility have been put forward.

From the analysis of the distributional range of this verb class, the following conclusions derive:

The analysis in this paper has proved Levin's (1993) and Goldberg's (1995) taxonomic works incomplete, as the distributional range of contact-by-impact verbs displays a much richer variety of configurations than it has been claimed by these authors. This is why departing from these previous taxonomies a new classification of contact-by-impact verbs has been provided in section 3. This new taxonomy accounts for syntactic as well as semantic characteristics of the verbs under study and it has been created with the purpose of offering a step forward in the categorization of contact-by-impact verbs, with the idea of being enriched with new predicates and parameters in further advancements on the study of such predicates.

As has been shown, actual cognitive complexities of the intransitive-motion construction have been largely ignored in Constructional Grammar discussions. In this manner, most contact-by-impact verbs have been proved compatible with the intransitive-motion construction according to corpus data. This integration of semantically transitive verbs by origin into an intransitive sentence is possible by applying different high-level metaphors such as A COMMUNICATIVE ACTION IS AN EFFECTUAL ACTION, CHANGES OF STATE ARE CHANGES OF LOCATION or AN ACTIVITY IS AN (EFFECTUAL) ACCOMPLISHMENT, which allow us to interpret the originally transitive predicates in terms of intransitive structures of the intransitive-motion kind. Other external constraints operating in the subsumption of contact-by-impact verbs into the intransitive-motion configuration are high-level metonymies, such as CONTROLLER FOR CONTROLLED that allows us for example to interpret the movement of a horse as if it was the movement of the person controlling the 
horse (e.g. Bob trotted his mount into position and kicked forward into an accelerating gallop).

Another interesting finding is that all contact-by-impact verbs that are related to sound are licensed into the intransitive-motion construction. This is the case for instance, with verbs such as batter, bump, crack, hammer, knock, slap, smack, tap, and thump. Corpus search reveals that these verbs merge the action performed by the subject with the sound produced by that action. Such intransitive sentences are licensed thanks to the use of the high-level metonymy RESULT FOR ACTION, in which the resulting sound is taken as the action performed by the subject (e.g. She headed for the door at a dead run, her new arm thumping uselessly against various items of furniture).

Finally, this study should be complemented by taking a larger number of verbs of contact by impact into account. Our classification is based on Faber and Mairal's (1999) 35 contact-by-impact verbs taxonomy, but Levin's (1993), for instance, includes as many as 60 contact-by-impact predicates. Future studies would have to find a way of integrating the additional 25 predicates into our taxonomy, attending to the verbs' pragmatic and semantic properties. We believe this would require new criteria for their categorization and could account for a better taxonomy of the verbs under study. Another potential line for further research is the investigation of the subsumption constraints on contact-by-impact predicates in relation to additional constructions, such as the resultative configuration, for which corpus data reveals a high number of examples.

\section{Acknowledgements}

The research on which the paper is based has received financial support from the Spanish Ministry of Economy and Competitiveness, grants FFI2010-17610/FILO and FFI2013-43593-P. This work is associated with the Center for Research in the Applications of Language (CRAL), University of La Rioja. 
References

Faber, P. B. and R. Mairal Usón. 1999. Construction a Lexicon of English Verbs. Berlin/New York: Mouton de Gruyter.

Fellbaum, Christiane. (ed.) 1998. WordNet: An Electronic Lexical Database. Cambridge: MIT Press.

Fillmore, C.J. 1970. “The grammar of Hitting and Breaking”. In R. Jacobs and P. Rosenbaum (eds.). Reading in English Transformational Grammar. 120-133

Gao, H. and C. Cheng. 2003. "Verbs of contact-by-impact in English and their equivalents in Mandarin Chinese.” Language and Linguistics 4. 3: 485-508.

Goldberg, A. 1995. Constructions: A Construction Grammar Approach to Argument Structure. Chicago: University Press.

Goldberg, A. 2006. Constructions at work: the nature of generalization in language. Oxford: Oxford University Press.

Goldberg, A. and R. Jackendoff. 2004. "The English Resultative as a family of constructions”. Language 80. 3: 532-568.

Jackendoff, R. 1990. Semantic structures. Cambridge/MA: MIT Press.

Kuno, S. and K. Takami. 2004. Functional Constraints in Grammar: On the Unergative-Unaccusative Distinction. Amsterdam/Philadelphia: John Benjamins.

Lakoff, G. 1987. Women, Fire and Dangerous Things. Chicago/London: University of Chicago Press.

Lakoff, G. 1993. “The contemporary theory of metaphor”. In Andrew Ortony (ed.). Metaphor and Thought. Cambridge: Cambridge UP. 202-251.

Lakoff, G. and M. Johnson. 1980. Metaphors We Live By. Chicago: The University of Chicago Press.

Lakoff, G. and M. Johnson. 1999. Philosophy in the Flesh: The Embodied Mind and Its Challenge to Western Thought. New York: Basic Books.

Lakoff, G. and M. Turner. 1989. More than Cool Reason: a Field Guide to Poetic Metaphor. Chicago: University of Chicago Press.

Levin, B. 1993. English Verb Classes and Alternations: A Preliminary Investigation. Chicago: University of Chicago Press.

Luzondo, A. 2007. "Semantic constraints on the caused-motion construction”. EPOS XXIII: $167-180$. 
Mairal Usón, R. 2002. “Why the notion of Lexical Template?”. Anglogermánica Online 1. Revista Electrónica Periódica de Filología Alemana e Inglesa.

Mairal Usón, R. and F. J. Ruiz de Mendoza Ibáñez. 2009. "Levels of description and explanation in meaning construction”. In Christopher S. Butler and J. M. Arista (eds.). Deconstructing Constructions. Amsterdam/Philadelphia: John Benjamins. 153-198.

Miller, George A., Richard Beckwith, Christian Fellbaum, Derek Gross, and Katherine J. Miller. 1990. Introduction to WordNet: An on-line lexical database. International Journal of Lexicography 3:235-244.

Navarro i Ferrando, I. 2011. "Lexical decomposition of English spatial particles and their subsumption in motion constructions”. Language Value, 3. 1: 114-137.

Pérez-Hernández, L. 1996. "The cognition of requests." Estudios Ingleses de la Universidad Complutense 4:189-208.

Pérez-Hernández, L. 2009. Análisis léxico-construccional de verbos de habla. Círculo de Lingüística Aplicada a la Comunicación 40:62-92.

Pérez-Hernández, L. 2012. "Saying something for a particular purpose: construccional compatibility and constructional families." RESLA 25: 189-210.

Pérez-Hernández, L. 2013. "Illocutionary constructions: (multiple source)-in-target metonymies, illocutionary ICMs, and specification links." Language \& Communication 33(2):128-149.

Pérez-Hernández, L. and M. S. Peña Cervel. 2009. "Pragmatic and cognitive constraints on lexical-constructional subsumption" ATLANTIS. Journal of the Spanish Association of Anglo-American Studies. 31. 2: 57-73

Pérez-Hernández, L. and F.J. Ruiz de Mendoza Ibáñez. 2011. “A LexicalConstructional Model account of illocution” Vial: Vigo International Journal of Applied Linguistics 8. 99-137.

Princeton University. 1997. Word Net version 1.6. Software.

Ruiz de Mendoza Ibáñez, F. J. 1999. Introducción a la Teoría Cognitiva de la Metonimia. Granada: Método Ediciones.

Ruiz De Mendoza Ibáñez, F.J. and J. L. Otal Campo. 2002. Metonymy, Grammar, And Communication. Granada: Comares.

Ruiz de Mendoza Ibáñez, F. J. and R. Mairal Usón. 2006. “Levels of semantic 
representation: where lexicon and grammar meet”. Interlingüística 17. 26-47.

Ruiz de Mendoza Ibáñez, F. J. and R. Mairal Usón. 2007. "High-level metaphor and metonymy in meaning construction”. In G. Radden, K.M. Köpcke, T. Berg, and P. Siemund (Eds.). Aspects of Meaning Construction in Lexicon and Grammar. Amsterdam/Philadelphia: John Benjamins. 33-49.

Ruiz de Mendoza Ibáñez, F. J. and R. Mairal Usón. 2008a. "Levels of description and constraining factors in meaning construction: an introduction to the Lexical Constructional Model”. Folia Linguistica. Acta Societatis Linguisticae Europaeae 42. 2: 355-400.

Ruiz de Mendoza Ibáñez, F. J. and R. Mairal Usón. 2008b. "New challenges for lexical representation with the Lexical-Constructional Model”. Revista Canaria de Estudios Ingleses 57.

Ruiz de Mendoza Ibáñez, F. J. and R. Mairal Usón. 2011. “Constraints on syntactic alternation: lexical-constructional subsumption in the Lexical-Constructional Model”. In Pilar Guerrero (ed.). Morphosyntactic Alternations in English. Functional and Cognitive Perspectives. Equinox.

Ruiz de Mendoza, F.J. and L. Pérez Hernández. 2001. "Towards a pragmaticallyoriented cognitive functional grammar. Revista Canaria de Estudios Ingleses 42. 187-214.

Talmy, L. 1985. "Lexicalization patterns: Semantic structure in lexical forms". In Timothy Shopen (ed.). Language Typology and Syntactic Description 3. Cambridge: Cambridge University Press. 36-149.

Talmy, L. 2000. Toward a Cognitive Semantics. Volume 1: Concept Structuring Systems. Volume 2: Typology and Process in Concept Structuring. Cambridge, MA: MIT Press.

Van Valin, R. D., Jr. 2005. The Syntax-Semantics-Pragmatics Interface: An Introduction to Role and Reference Grammar. Cambridge: Cambridge UP.

Van Valin, R. D., Jr. and R. LaPolla. 1997. Syntax, Structure, Meaning and Function. Cambridge: Cambridge UP.

Received: October 10, 2013

Accepted: April 13. 2015

Published: September 28, 2015 